\title{
Application of a novel approach to modelling the supercritical extraction kinetics of oil from two sets of chia seeds
}

\author{
David Villanueva-Bermejo ${ }^{\mathrm{a}, *}$, Tiziana Fornari ${ }^{\mathrm{a}}$, Maria V. Calvo ${ }^{\mathrm{a}}$, Javier Fontecha ${ }^{\mathrm{a}}$, \\ Jose A.P. Coelho ${ }^{\mathrm{b}, \mathrm{c}}$, Rui M. Filipe ${ }^{\mathrm{b}, \mathrm{d}}$, Roumiana P. Stateva ${ }^{\mathrm{e}}$ \\ ${ }^{a}$ Instituto de Investigación en Ciencias de la Alimentación CIAL (CSIC-UAM), 28049 Madrid, Spain \\ b Instituto Superior de Engenharia de Lisboa, Instituto Politécnico de Lisboa, 1959-007 Lisboa, Portugal \\ c Centro de Química Estrutural, Instituto Superior Técnico, Universidade de Lisboa, 1049-001 Lisboa, Portugal \\ d CERENA, Centro de Recursos Naturais e Ambiente, Instituto Superior Técnico, Universidade de Lisboa, 1049-001 Lisboa, Portugal \\ e Institute of Chemical Engineering, Bulgarian Academy of Sciences, 1113 Sofia, Bulgaria
}

\section{A R T I C L E I N F O}

Article history:

Received 7 January 2019

Received in revised form 11 October 2019

Accepted 25 October 2019

Available online 12 November 2019

\section{Keywords:}

Chia seed oil

Supercritical $\mathrm{CO}_{2}$ extraction

Polyunsaturated fatty acids (PUFA)

$\alpha$-Linolenic acid (ALA)

Extraction kinetics

Mathematical modelling

\section{A B S T R A C T}

The kinetics of the supercritical fluid extraction of edible and discarded chia seeds was studied and modelled for the first time. The total oil was removed at $45 \mathrm{MPa}$ and $60^{\circ} \mathrm{C}$ after $240 \mathrm{~min}$. The extraction kinetics was simulated using a dynamic model in gPROMS ModelBuilder environment and the kinetic parameters estimated. Triolein was chosen as a model compound of the chia oil. The agreement between the experimental yields and those calculated by the model was good with deviations in the range (1.2-6.6) \%, except at $25 \mathrm{MPa}$ and $60^{\circ} \mathrm{C}(\mathrm{AARD}=9.5 \%)$.

(c) 2019 The Korean Society of Industrial and Engineering Chemistry. Published by Elsevier B.V. All rights reserved.

\section{Introduction}

At present, there is a constant search of promising and inexpensive vegetal materials as a source of polyunsaturated fatty acids (PUFAs). Chia (Salvia hispanica L.), a plant indigenous to Guatemala and Mexico, which belongs to the Lamiaceae family, is attracting a great attention, especially the seeds. Chia seeds are being studied as a source of food ingredients, such as proteins and dietary fiber [1-3], but they mainly stand out for their high oil content (20-35 mass \%). Chia seed oil contains significant amounts of PUFAs, mainly the omega-3 $\alpha$-linolenic acid (ALA) (60-65\% of total fatty acids) [4], which role in the prevention of cardiovascular, nervous system and inflammatory diseases has been thoroughly described $[5,6]$.

Thus far, different solvents (ethyl acetate, acetone, propane, petroleum ether and hexane) and extraction techniques (cold and hot pressing, Soxhlet, Ultrasound-Assisted Extraction and Pressurized Liquid Extraction) have been applied to obtain chia seed oil [7-11]. A viable and eco-friendly alternative to the use of organic toxic solvents is the extraction with supercritical $\mathrm{CO}_{2}\left(\mathrm{scCO}_{2}\right)$, which is non-toxic, non-flammable, non-mutagenic and carcinogenic and is abundant

\footnotetext{
* Corresponding author.

E-mail address: david.villanueva@uam.es (D. Villanueva-Bermejo).
}

and inexpensive. Moreover, due to the possibility of working at low temperatures and in the absence of oxygen, supercritical extraction with $\mathrm{scCO}_{2}$ (SCE) prevents or minimizes the degradation of bioactive compounds and allows obtaining solvent-free products [12]. New developments regarding the application of this advanced technique to obtain oils were reported recently in the literature. For example, Wei et al. [13] employed ultrasound-assisted supercritical carbon dioxide extraction for removing oleanolic acid and ursolic acid from Hedyotis corymbose. The experimental solubility data, called by the authors fictitious, were read from the initial slope of the curve of the extraction yield versus the amount of $\mathrm{scCO}_{2}$ used, and were modelled applying several semi-empirical density-based models. Moon et al. [14] studied the $\mathrm{scCO}_{2}$ extraction, with and without cosolvent (ethanol) of the essential oil from Asiasarum heterotropoides and the results obtained were compared with conventional extraction. In another study [15], turmeric (Curcuma longa L.) was extracted with $\mathrm{scCO}_{2}$ and turmerones were concentrated using semi-preparative supercritical chromatography. Supercritical fluid extraction with a co-solvent was also applied to extract oil from rice bran with the aim to promote the valorization of this abundant feedstock [16]. Concerning SCE of chia seed oil, as far as we are aware, only a few studies have been carried out till present [17-20]. In those, the concentration of ALA achieved in the extracted oil was approximately (60-65) \%, hence SCE process allowed obtaining 
healthy and high-quality oils regardless of the operational parameters applied.

It is known that kinetic data are essential for the realization of a feasible industrial process. However, despite the aforementioned and the possibilities to realize a viable industrial process, kinetic data are not only scarce and superficial, but also, as far as we are aware, there are no attempts related to the modelling of SCE of oil from chia seeds reported in the literature till present. Accordingly, two were the objectives of this work: $i$ ) to provide new data on the $\mathrm{scCO}_{2}$ extraction of chia oil and ii) to apply a novel approach to the extraction kinetics modelling, advocated originally by Sovová and Stateva [21]. This approach reflects the interaction between kinetics and phase equilibria (solubility) and applies a reliable and versatile modelling framework to estimate the solubility of the oil in the supercritical fluid, as discussed in detail in Section "Supercritical fluid extraction of chia oil - modelling framework".

To achieve the objectives of our work, edible chia seeds (ECS), and discarded seeds (DCS) were studied. Particularly for the latter, the present investigation can be of considerable interest as it will provide information on how to intensify further their valorization and industrial applications. So far, the studies reported in the literature have been carried out by using ECS. Chia seeds employed in the present study were subjected to a selection process in which the seeds were classified in different qualities mainly based on their weight, intactness, color, visual aspect and size. Thus, DCS consist of damaged, partially broken and/or smaller-size and lower-weight seeds that are usually discarded during post-harvest handling and finally intended to animal feeding. Their price, as a consequence of the market surplus of this product, is considerably lower than that of ECS. Even though they are an underutilized raw material, DCS possess a noteworthy amount of oil and may constitute a viable alternative source for obtaining highly polyunsaturated chia seed oils to be used in human health care formulations.

\section{Materials and methods}

\section{Sample preparation}

The two different sets of chia seeds (Salvia hispanica L.) originating from Mexico were purchased from a local supplier (Primaria). The oil content for each set of seeds (28.3\% and $19.9 \%$ mass for ECS and DCS, respectively) was determined by pressurized liquid extraction by using a 2:1 chloroform:methanol mixture at $60^{\circ} \mathrm{C}$ and $10 \mathrm{~min}$ of extraction time [22]. These results are in agreement with the values provided by the supplier for each set ( $25.2 \%$ and $20.6 \%$, respectively). In what follows we will use the oil content values obtained by us for each set of seeds.

The seeds were ground in a knife mill cooled by liquid nitrogen. Ground seeds were sieved using mesh sizes of 0.250 and $0.500 \mathrm{~mm}$ $\varnothing$ (CISA Cedaceria Industrial S.L. Barcelona, Spain). An average particle diameter $\left(d_{p}\right)$ of $0.370 \mathrm{~mm}$ was obtained, using Eq. (1):

$d_{p}=\frac{M_{t}}{\sum_{i=1}^{j} \frac{m_{i}}{d_{p i}}}$

where $M_{t}$ is the total mass of milled seeds, $m_{i}$ - the mass of the particles kept below mesh size $d_{p i}$ and $j-$ the number of mesh sizes.

Samples obtained were stored at $-20^{\circ} \mathrm{C}$ until their use.

\section{Chemicals}

Dichloromethane, hexane, methanol, acetonitrile, dimethylformamide (HPLC grade) and sulfuric acid (98\% purity) were purchased from Labscan (Dublin, Ireland). Sodium carbonate, sea sand and sodium sulfate anhydrous were supplied by Panreac (Barcelona, Spain). Sodium methoxide (95\% purity) was supplied by Sigma-Aldrich (St. Louis, MO, USA). Butterfat BCR-164 (EU Commissions; Brussels, Belgium) was supplied by Fedelco Inc. (Madrid, Spain). $\mathrm{CO}_{2}$ (99.99\% purity) was supplied by Carburos Metálicos (Madrid, Spain).

\section{Supercritical $\mathrm{CO}_{2}$ extraction}

The SCEs were performed in a pilot-plant supercritical fluid extractor (model SF2000; Thar Technology, Pittsburgh, PA, USA), equipped with a $273 \mathrm{~cm}^{3}$ cylinder extraction cell $(18.8 \mathrm{~cm}$ long and $4.3 \mathrm{~cm}$ internal diameter) and two separators ( $0.5 \mathrm{~L}$ capacity). A thorough description of the equipment can be found in VillanuevaBermejo et al. [23].

The SCEs from DCS were carried out at $p=(25$ and 45) MPa and $T=(40 \text { and } 60)^{\circ} \mathrm{C}$. The $\mathrm{CO}_{2}$ flow rate and extraction times were, respectively, $40 \mathrm{~g} \mathrm{~min}^{-1}$ and $240 \mathrm{~min}$ for all the experiments with this set of seeds. The extractions of ECS were performed at $45 \mathrm{MPa}$ and $40{ }^{\circ} \mathrm{C}$. Several $\mathrm{CO}_{2}$ flow rates were studied, namely 27,40 and $54 \mathrm{~g} \mathrm{~min}^{-1}\left(\mathrm{CO}_{2}\right.$-to-seed ratio of 50, 74 and 100, respectively). For all runs, the seeds mass used was $130 \mathrm{~g}$, with an apparent density value of $0.606 \pm 0.002 \mathrm{~g} \mathrm{~cm}^{-3}$. During the experiments the $\mathrm{scCO}_{2}$ was recirculated. The entire extracts were collected from the first separator (the mass of oil obtained from the second separator was negligible) by depressurization at $5 \mathrm{MPa}$ (system recirculation pressure). Oil samples were dissolved in methylene chloride, treated with $\approx 1 \mathrm{~g}$ of sodium sulfate anhydrous and filtered through $0.45 \mu \mathrm{m}$ filters. Finally, the samples were stored at $-35^{\circ} \mathrm{C}$ until analysis.

\section{Fatty acid profile}

The derivatization of fatty acids from chia oils was carried out following the method described by Castro-Gómez et al. [24]. The analysis of fatty acid methyl esters (FAMEs) were performed in an Agilent chromatograph $6890 \mathrm{~N}$ (Agilent Technologies Inc. Palo Alto, USA) equipped with an MS detector (Agilent 5973N) and using CPSil 88 fused-silica capillary column $(100 \mathrm{~m} \times 0.25 \mathrm{~mm}$ ID $\times 0.2 \mu \mathrm{m}$. Chrompack, Middelburg, The Netherlands). The temperature program started at $100^{\circ} \mathrm{C}$ for $1 \mathrm{~min}$ and then the temperature increased by $7^{\circ} \mathrm{C} \mathrm{min}^{-1}$ up to $170^{\circ} \mathrm{C}$, followed by an isothermal period of $55 \mathrm{~min}$. Finally temperature increased by $10^{\circ} \mathrm{C} \mathrm{min}^{-1}$ up to $230^{\circ} \mathrm{C}$ and was held for $33 \mathrm{~min}$. The injector temperature was $250{ }^{\circ} \mathrm{C}$ and helium was used as the carrier gas. The analysis was carried out in split mode (split ratio 1:25) and the injection volume was $1 \mu \mathrm{L}$. For the MS detector, the transfer line, source and quadrupole temperatures were $250^{\circ} \mathrm{C}, 230^{\circ} \mathrm{C}$ and $150^{\circ} \mathrm{C}$, respectively. The mass spectrometer operated under electron impact mode $(70 \mathrm{eV})$. Eluting compounds were scanned in total ion current (TIC) mode in the mass range from 40 to $500 \mathrm{mz}^{-1}$. The identification of target compounds was carried out by comparing their mass spectra with those at the National Institute of Standards and Technology (NIST) library (Gaithersburg, MD, USA). The response factors were calculated using anhydrous milk fat (reference material BCR-164). Tritridecanoin (C13:0) was used as an internal standard.

\section{Supercritical fluid extraction of chia oil - modelling framework}

\section{Model description}

The model developed by Sovová and Stateva [21] for multicomponent systems was used in this work. In brief, the approach reflects the interplay between solubility and kinetics. For that purpose, a rigorous thermodynamic model is applied to 
estimate the solubility of the oil in the supercritical fluid, and the resulting equations are incorporated into the dynamic model. Dynamic simulation of the supercritical extraction process is then performed. The model considers that the concentrations inside the extractor are homogeneous in the fluid and solid phases. Internal diffusion is neglected based on the assumption that the extracts are located at the surface of the solid particles, and hence easily available.

As the chia seeds used in our work were grounded to an average diameter of $0.370 \mathrm{~mm}$, it was considered that the resulting internal diffusion path for such small particles is short. Consequently, the oil is easily available at the particle surface.

The model is described by the following set of equations:

$\frac{d w}{d t}+\frac{w}{t_{r}}=\frac{k_{f} a_{0}}{\varepsilon}\left(w^{+}-\mathrm{w}\right)$

$\frac{d w_{s}}{d t}=-q^{\prime} t_{r} \frac{k_{f} a_{0}}{\varepsilon}\left(w^{+}-w\right)$

$w^{+}=K w_{s}+\frac{w_{s}^{b}}{w_{t}^{b}+w_{s}^{b}}\left(w_{s a t}-K w_{s}\right)$

with the initial conditions:

$w(0)=w_{0}$

$w_{s}(0)=w_{s, 0}$

The yield, $e\left(\mathrm{~kg} \mathrm{~kg}^{-1}\right.$ solid), is defined by:

$e=q^{\prime} \int_{0}^{t} e d t$

$e(0)=0$

where $w$ is the oil concentration in the fluid phase inside the extractor $\left(\mathrm{kg} \mathrm{kg}^{-1} \mathrm{CO}_{2}\right), w_{s}$ - the oil concentration in the solid phase ( $\mathrm{kg} \mathrm{kg}^{-1}$ solid), $t$ and $t_{r}$ are the extraction and residence time (min), respectively, $q^{\prime}-$ the specific flow rate $\left(\mathrm{kg} \mathrm{CO}_{2} \mathrm{~min}^{-1} \mathrm{~kg}^{-1}\right.$ solid $)$, $w^{+}-$the oil concentration at solid-fluid interface $\left(\mathrm{kg} \mathrm{kg}^{-1} \mathrm{CO}_{2}\right)$, $\varepsilon$ - void fraction in the bed, $k_{f} a_{0}\left(\mathrm{~min}^{-1}\right)-$ the volumetric fluid phase mass transfer resistance, $K\left(\mathrm{~kg}\right.$ plant $\left.\mathrm{kg}^{-1} \mathrm{CO}_{2}\right)$ - the partition coefficient, $w_{t}\left(\mathrm{~kg} \mathrm{~kg}^{-1} \mathrm{CO}_{2}\right)$ - the monolayer adsorption maximum content, $w_{\text {sat }}\left(\mathrm{kg} \mathrm{kg}^{-1} \mathrm{CO}_{2}\right)$ - the solubility of the free oil compound, and $b$ is a coefficient that should be higher than one.

The model was deployed in gPROMS ModelBuilder [25], an equation-oriented modelling environment for dynamic (and steady-state) simulation that includes optimization and parameter estimation capabilities. It should be noted that the use of this kind of equation-oriented modelling and optimization software for supercritical $\mathrm{CO}_{2}$ extraction has not been that much reported in the literature until now.

Some of the coefficients in the model are unknown and parameter estimation was performed to estimate these missing values. The simulated yield profiles were compared with the experimental data, and an objective function was used to minimize the error of the adjustment, and obtain the parameter values that result in the best fit. Obtaining the solution of the resultant nonlinear dynamic model may be challenging and may cause numerical convergence problems. Also, locating the global optimum is not guaranteed. A shortage in experimental data may also compromise the reliability of the results and the confidence interval associated with the solutions.
In this work, gPROMS ModelBuilder parameter estimation capabilities were used to obtain the unknown parameters. gPROMS parameter estimation uses a maximum likelihood problem to obtain the missing parameters. The interested reader can find more details on gPROMS documentation [25].

To be able to relate the fitting accuracy achieved, a standard measure of deviation was used, the absolute average relative deviation, AARD, defined by:

$\mathrm{AARD}=\frac{100}{\mathrm{~N}} \sum_{j=1}^{N} \frac{\left|e_{i}^{\text {exp }}-e_{i}^{\text {est }}\right|}{e_{i}^{\exp }}$

where $N$ is the total number of experimentally measured points, $e_{i}^{e x p}$ and $e_{i}^{e s t}$ are the $i$-th experimental and estimated point, respectively.

Representation of the oil and correlation of its solubility in $\mathrm{scCO}_{2}$

The chia seed oil, as any other vegetable oil, is a very complex mixture of many compounds, mainly triacylglycerols (TAGs) with minor amounts of other compounds such as free fatty acids, monoand diacylglycerols [26,27]. With the purpose of reducing the size of the kinetics modelling task, a generally accepted approach is to exemplify the vegetable oil examined either by one TAG only [28-30], or as a binary mixture of triolein and oleic acid [31]. Recently, there were attempts to represent some vegetable oils as a mixture of several TAGs, with a varied success - from a failure in the prediction of the phase equilibrium of the multicomponent mixture examined [32] to an acceptable quantitative and qualitative representation of the kinetic curves measured [33].

In the case of chia seed oil, our analyses show that linolenic acid is the fatty acid with the highest content followed by linoleic acid. Hence, the TAGs trilinolenin and trilinolein are the main lipid representatives in the oil.

To simulate the extraction kinetics of oil from the chia seeds, the phase behavior of the system (oil and $\mathrm{scCO}_{2}$ ) should be modeled, which requires an appropriate thermodynamic model by which the solubility of the oil in the $\mathrm{scCO}_{2}$ will be calculated. Then, following the algorithm advocated in Sovova and Stateva [21], a second order polynomial function will be fitted to the solubility data and implemented in the dynamic model.

Generally, equations of state (EoSs) are the usual choice for calculation of solubility of a compound (mixture of compounds) in $\mathrm{scCO}_{2}$. Their application requires knowledge of the critical temperature and pressure of the pure compounds comprising the mixture. It should be noted, however, that in many cases of complex systems, which, for different reasons, have to be represented by a model compound(s), not always the most appropriate one(s) is chosen, because of the lack of information on its (their) critical properties.

In our case, the most suitable representative of chia seed oil, following the results of the analyses, is the TAG trilinolenin. Having said that, however, two very important issues should be taken into consideration: $i$ ) lack of any experimental information on the VLE of trilinolenin $+\mathrm{scCO}_{2}$; $i$ i) total lack of data (both experimental and estimated) on the thermophysical properties of trilinolenin.

Hence, though trilinolenin is the most adequate representative of the chia seed oil, the uncertainties that will be intertwined into the solubility predictions via its estimated properties could be so substantial that they might lead to a misrepresentation of the VLE of the binary (trilinolenin $+\mathrm{scCO}_{2}$ ), e.g. to an erroneous prediction of the extent of the vapour-liquid region, which, however, could not be identified and verified (see issue $i$ ).

In view of the above, we chose triolein as the TAG to represent the chia seed oil, which was motivated by two reasons: 1) there are experimental data available on the VLE of the binary triolein $+\mathrm{scCO}_{2}$ and 2) the estimated thermophysical parameters 
(a)

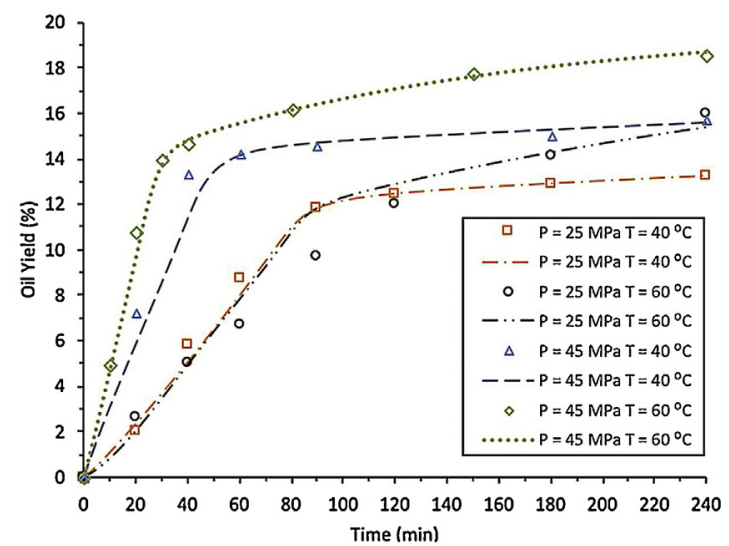

(b)

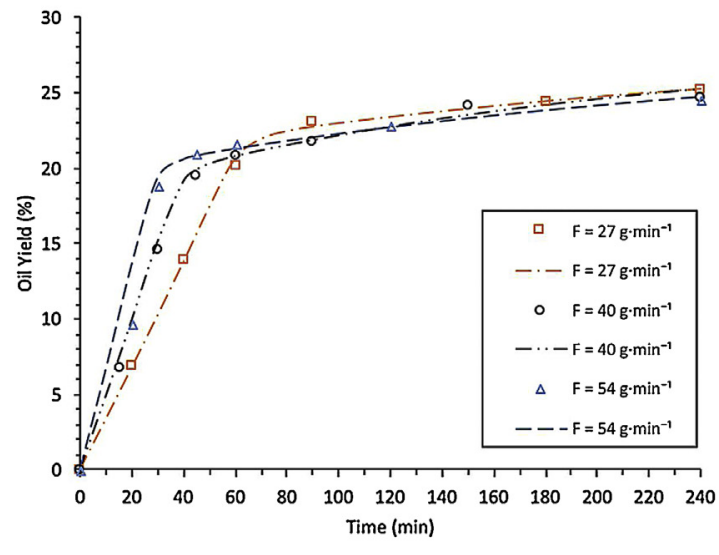

Fig. 1. Experimental (symbols) and simulated (lines) cumulative extraction curves obtained for (a) $\mathrm{DCS}$ ( $40 \mathrm{~g} \mathrm{~min}^{-1} \mathrm{CO}_{2}$ flow rate), and (b) ECS ( $45 \mathrm{MPa}$ and $40{ }^{\circ} \mathrm{C}$ ).

of triolein used by us have been proved to represent in an acceptable way the VLE of the system [33].

The solubility (mole fraction) of a compound in the SC fluid may be expressed as:

$y_{i}=\frac{x_{i} \varphi_{i}^{L}}{\varphi_{i}^{V}}$

where $\varphi_{i}^{L}$ and $\varphi_{i}^{V}$ are the fugacity coefficients of triolein, representing the chia oil in our case, in the liquid and SC fluid phase, respectively.

We employ the predictive Soave-Redlich-Kwong (PSRK) cubic EoS [34] to calculate the fugacity coefficients of triolein in the liquid and vapor phases, respectively, and use the values for its critical temperature and pressure reported by Coelho et al. [33].

\section{Results and discussion}

\section{Supercritical $\mathrm{CO}_{2}$ extraction}

The experimental kinetic curves, obtained for the SCE of chia oil from DCS and ECS are displayed on Fig. 1a and b, respectively. For DCS, the extraction yield (mass of oil/mass of seeds) increased with pressure and temperature, and was in the range from $13.3 \%$ (at $25 \mathrm{MPa}$ and $40^{\circ} \mathrm{C}$ ) to $18.6 \%$ (at $45 \mathrm{MPa}$ and $60^{\circ} \mathrm{C}$ ) after $240 \mathrm{~min}$ extraction time (Fig. $1 \mathrm{a}$ ).

At the experimental conditions studied in this work, a crossover effect on the overall extraction yield was not observed. Rocha Uribe et al. [19] at operational conditions (27.2-40.8) MPa and (40-60) $\stackrel{\circ}{ }$, which are very similar to ours, reported analogous behavior pattern, while Ixtaina et al. [18] observed a crossover point within the same range of pressures (25-45) MPa and temperatures (40-60) $\stackrel{\circ}{ } \mathrm{C}$ as those studied by us.

Considering the total oil (19.9\% mass) contained in DCS, the recovery values (mass of oil extracted/mass of oil in the seeds) achieved in this work ranged from (66.7-93.5) \%, and are consonant with the results reported by Ixtaina et al. [17,18] and Scapin et al. [20], who employed high-quality chia seeds containing (32-34) \% mass of oil, from different geographical origins, as a raw material.

Fig. $1 \mathrm{~b}$ shows the $\mathrm{CO}_{2}$ flow rate effect on the oil yield when ECS are used. Pressure and temperature were set at $45 \mathrm{MPa}$ and $40^{\circ} \mathrm{C}$, respectively. The reasons behind choosing these particular experimental conditions were that they proved to be the optimal ones for obtaining higher oil recoveries and ALA concentrations from DCS (see Section "Analysis of fatty acid composition").
As shown (Fig. 1b), extraction curves overlap at the end of the extraction process, and hence similar oil extraction yields (24.6-25.2)\% were achieved independently of the $\mathrm{CO}_{2}$ flow rate applied. Taking into consideration that the initial oil content for ECS was $28.3 \%$ mass, and that the recoveries obtained were between (86.9-89.9) \%, it can be concluded that practically all available oil was extracted after the extraction time ( $240 \mathrm{~min})$. Nevertheless, during the early stages of the extraction, when the free oil located on the surface of the seeds is extracted and the mass transfer resistance is negligible, the extraction rate increased with the $\mathrm{CO}_{2}$ flow. At that point, the mass of oil extracted at the lowest $\mathrm{CO}_{2}$ flow rate $\left(0.44 \mathrm{~g} \mathrm{~min}^{-1}\right)$ was 1.7 -fold higher than the obtained at the highest flow rate $\left(0.76 \mathrm{~g} \mathrm{~min}^{-1}\right)$.

\section{Analysis of fatty acid composition}

Fig. 2 shows the fatty acid composition of oils from both sets of chia seeds. ALA was the main fatty acid (55.58-67.45\%) in the oils, followed by linoleic acid (17.2-23.5\%). In respect of DCS (Fig. 2a),

(a)

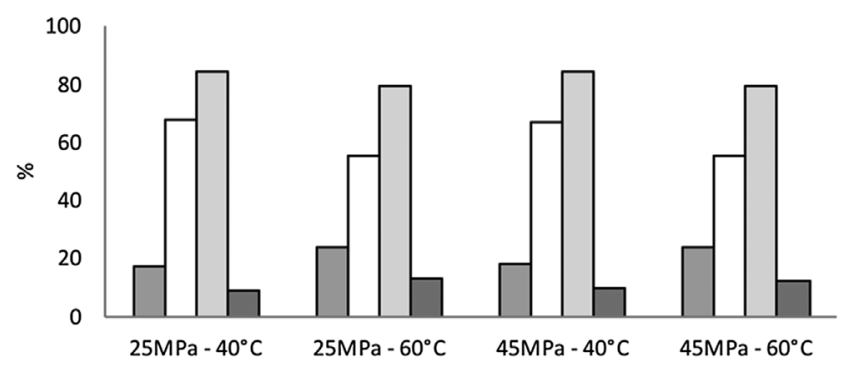

(b)

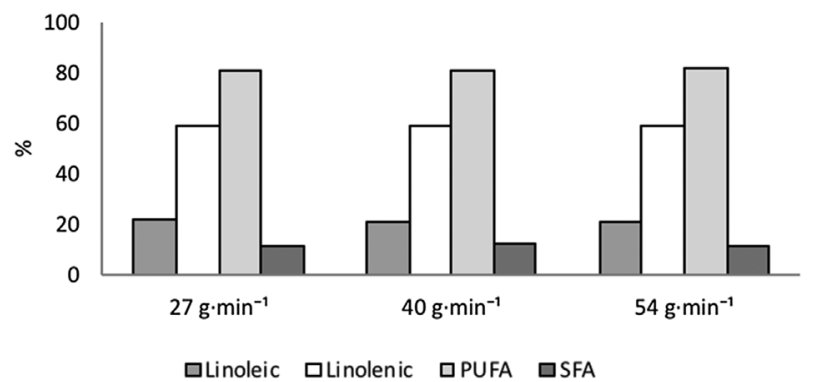

Fig. 2. Fatty acid composition (\% of total fatty acids) of oils extracted from (a) DCS ( $40 \mathrm{~g} \mathrm{~min}^{-1} \mathrm{CO}_{2}$ flow rate) and (b) ECS ( $45 \mathrm{MPa}$ and $40^{\circ} \mathrm{C}$ ). Extraction time: $240 \mathrm{~min}$. 
Table 1

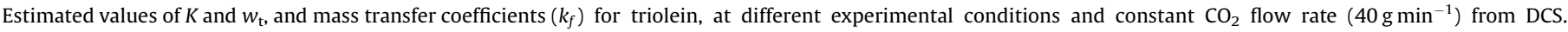
The AARDs represent the deviations between the experimental and calculated yield values.

\begin{tabular}{|c|c|c|c|c|c|}
\hline$P(\mathrm{MPa})$ & $T\left({ }^{\circ} \mathrm{C}\right)$ & $K\left(\right.$ kg plant $\left.\mathrm{kg}^{-1} \mathrm{CO}_{2}\right)$ & $k_{f}\left(\min ^{-1}\right)$ & $w_{t}\left(\mathrm{~kg} \mathrm{~kg}^{-1} \mathrm{CO}_{2}\right)$ & AARD (\%) \\
\hline 25 & 40 & $3.22 \mathrm{E}-3$ & $1.51 \mathrm{E}-5$ & $8.04 \mathrm{E}-2$ & 4.82 \\
\hline 25 & 60 & $1.36 \mathrm{E}-2$ & $3.08 \mathrm{E}-5$ & 8.04 E-2 & 9.49 \\
\hline 45 & 40 & $4.27 \mathrm{E}-3$ & 7.03E-4 & 5.76 E-2 & 5.64 \\
\hline 45 & 60 & $2.47 \mathrm{E}-2$ & $4.58 \mathrm{E}-4$ & $5.20 \mathrm{E}-2$ & 2.13 \\
\hline
\end{tabular}

Table 2

Estimated values of $K$ and $w_{t}$ for triolein at $45 \mathrm{MPa}$ and $40{ }^{\circ} \mathrm{C}$, and varying $\mathrm{scCO}_{2}$ flow rate for ECS. Triolein mass transfer coefficients $k_{f}=7.03 \mathrm{E}-4$. The AARDs represent deviations between the experimental and calculated yield values.

\begin{tabular}{llll}
\hline$F\left(\mathrm{~kg} \mathrm{~min}^{-1}\right)$ & $K\left(\mathrm{~kg} \mathrm{plant} \mathrm{kg}{ }^{-1} \mathrm{CO}_{2}\right)$ & $w_{t}\left(\mathrm{~kg} \mathrm{~kg}^{-1} \mathrm{CO}_{2}\right)$ & AARD (\%) \\
\hline 27 & $2.00 \mathrm{E}-2$ & $6.01 \mathrm{E}-2$ & 1.22 \\
40 & $1.69 \mathrm{E}-2$ & $8.25 \mathrm{E}-2$ & 2.47 \\
54 & $9.28 \mathrm{E}-3$ & $8.07 \mathrm{E}-2$ & 6.65 \\
\hline
\end{tabular}

the fatty acid profile was very similar for both pressures examined ( 25 and $45 \mathrm{MPa}$ ). With regard to the influence of temperature, the concentration of ALA in the extract was lower at $60^{\circ} \mathrm{C}(\mathrm{n}-6 / \mathrm{n}-3$ ratios around 0.26 and 0.42 at 40 and $60{ }^{\circ} \mathrm{C}$, respectively, data not shown). Likewise, the fatty acid profiles obtained from ECS at the different $\mathrm{CO}_{2}$ flow ratios (Fig. 2b) were very similar (PUFA and ALA concentrations around ( $81 \%$ and 59\%, respectively). Our results agree well with those of other authors, who used chia seeds from several geographical origins, and applied different extraction methods and operational conditions [7-11,17-20].

\section{Kinetics modelling results and discussion}

The model described in Section "Supercritical fluid extraction of chia oil - modelling framework" was solved in gPROMS to simulate the evolution of yield over time for the oil extracted from the two different sets of chia seeds, namely DCS and ECS, at the operational conditions of interest to the experiment.

For the ECS, the initial oil content of the matrix, $w_{\text {sum }}$, is $0.283 \mathrm{~kg} \mathrm{~kg}^{-1}$ solid, while for DCS $w_{\text {sum }, 0}$ is $0.199 \mathrm{~kg} \mathrm{~kg}^{-1}$ as discussed in Section "Supercritical fluid extraction of chia oil modelling framework".

There are four unknown parameters in the model: $b, k_{f}, w_{t}$ and $K$. As the number of experimental data points limits the number of model parameters that can be estimated within a reasonable confidence interval, predefined fixed values should be assigned to some of the above parameters.

The value of parameter $b$, which should be » 1 , was determined after some preliminary calculations and sensitivity analysis of its influence on the extraction kinetics modelling. It was verified that the best value was $b=40$, and hence it was used in the kinetics model for all cases of DCS and ECS examined.

The value of $k_{f}$ for each case studied was estimated following Coelho et al. [33], who used the relation of Wilke and Chang [35]. The $k_{f}$ values obtained were then set as constants in the kinetics model, thus reducing the degrees of freedom. For the DCS case, the best values of $k_{f}$ obtained are displayed in Table 1. For the ECS case, where pressure and temperature remain constant, a single $k_{f}$ value was used for the three $\mathrm{scCO}_{2}$ flow rates applied (Table 2).

Hence, the maximum content corresponding to monolayer adsorption, $w_{t}$, and the partition coefficient $K$ are the two model parameters left to be estimated by fitting the dynamic model to the experimental data.

The best estimated values of $K$ and $w_{t}$ are shown in Tables 1 and 2 , for the DCS and ECS cases, respectively.

For DCS, the influence of temperature on the partition coefficient is pronounced $-K$ increases by an order of magnitude with the increase of temperature, while the increase of $K$ values with pressure is not so noticeable (Table 1 ). This behavior shows that the bond between the solute and the matrix weakens with increasing temperature of extraction, which, in turn, leads to an increase in partition coefficient values, favoring thus the $\mathrm{CO}_{2}$ phase, while the adsorbent capacity generally decreases.

The influence of $\mathrm{scCO}_{2}$ flow rate on $\mathrm{K}$ is demonstrated for the case of SCE of ECS (Table 2). As shown, the values of $K$ decrease with the increase of $\mathrm{scCO}_{2}$ flow rate.

The deviations between the experimentally measured and the calculated yields, expressed by the AARDs (\%), are also shown (Tables 1 and 2, respectively). For the DCS case, there is a good qualitative and quantitative agreement between the simulated and experimental extraction yield curves, as demonstrated on Fig. 1a (a)

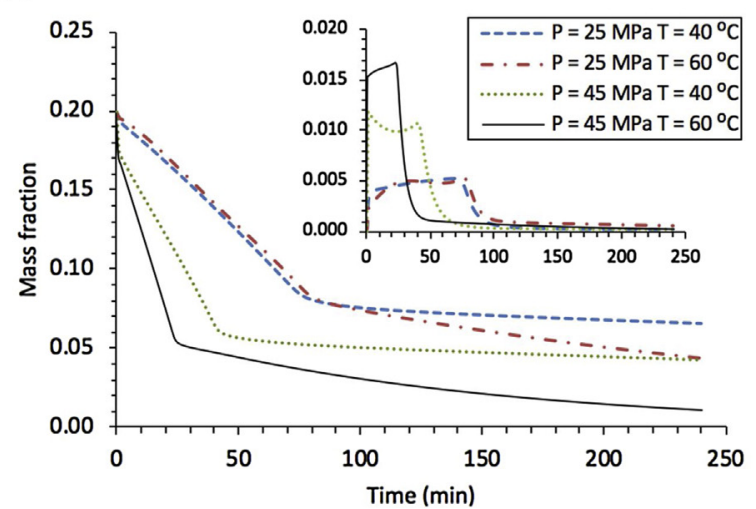

(b)

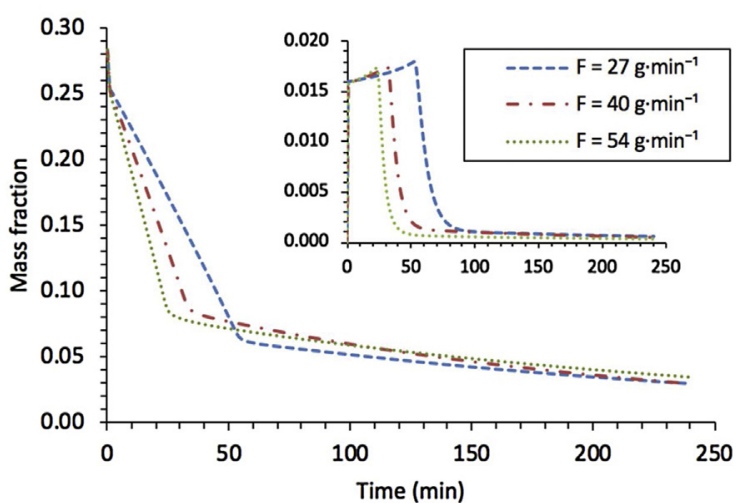

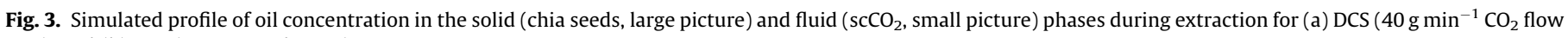
rate), and (b) ECS ( $45 \mathrm{MPa}$ and $40^{\circ} \mathrm{C}$ ). 
and Table 1 . The only exception being the case at $25 \mathrm{MPa}$ and $60^{\circ} \mathrm{C}$ where the AARD is higher. The latter was not unexpected taking into consideration the somewhat different trend of the particular experimental extraction curve in comparison to the other three.

For the ECS case, the simulated extraction curves follow very well the pattern of the experimental ones and overlap at the end of the extraction. Thus, the kinetics modelling results verify the experimentally observed fact that the oil extraction yields are not influenced by the $\mathrm{CO}_{2}$ flow rate applied. The AARD values obtained confirm the very good agreement between the experimental and simulated results (Table 2 ).

The evolution of the oil concentration during extraction in the solid matrix inside the extractor and in the exiting fluid stream was simulated. The results for DCS and ECS are presented in Fig. 3a and $b$, respectively.

As depicted in Fig. 3a, increasing the pressure leads to a faster and more efficient extraction. However, that effect is moderate at $40^{\circ} \mathrm{C}$ and at the first stage of the extraction, while it becomes more significant when the operating temperature is set to $60^{\circ} \mathrm{C}$.

Fig. $3 \mathrm{~b}$ shows a positive effect of the increased $\mathrm{scCO}_{2}$ flow rate on the speed of extraction. Thus, for ECS, on the one hand, the change of oil concentration in the solid phase follows the pattern observed for the DCS (Fig. 1a), and reaches the same final value regardless of the $\mathrm{CO}_{2}$ flow rate. On the other hand, a higher yield and lower solid phase concentration are being achieved with smaller flowrates.

As far as we are aware, these are the first data demonstrating the evolvement of the oil concentration in both the fluid and solid phases during $\mathrm{scCO}_{2}$ extraction of chia seeds. Taking into consideration that a single model compound is used to represent the oil, the results obtained are quite adequate. Furthermore, they provide valuable information to be used with confidence in a subsequent process design stage.

\section{Conclusions}

This work presents for the first time the results of modelling the experimental kinetics data of SCE of oil from two sets of chia seeds, ECS and DCS. The SCE experiments demonstrated that the highest oil yield (18.6\%) obtained from DCS was achieved at the highest pressure and temperature applied ( $45 \mathrm{MPa}$ and $60^{\circ} \mathrm{C}$ ). Furthermore, at these operational conditions practically all the oil was exhausted ( $93.5 \%$ oil recovery). As can be expected, the extraction yields achieved from ECS, as compared to those from DCS, were higher (24.6-25.2) \%, but their values were not influenced by the $\mathrm{CO}_{2}$ flow rate applied. Nevertheless, the increase in the $\mathrm{CO}_{2}$-to-chia mass ratio enhanced up to 1.7 times the oil extraction rate at the early stages of extraction. Concentrations of ALA in the range (55-67) \% in oils were attained. Furthermore, the oils obtained from both seeds (DCS and ECS) presented a similar fatty acid profile.

The kinetics modelling was performed applying a new approach, which intertwines the complex interaction between kinetics and solubility. For the purpose of modelling, triolein was chosen as chia seeds oil representative compound. The model equations were solved in gPROMS ModelBuilder environment, and parameter estimation was performed to obtain some model parameters.

The results obtained demonstrate that albeit the simplifications introduced in the model, there is a good agreement between the calculated and experimental extraction yields at the SCE operating conditions examined.

Finally, the valuable information on the mass transfer of the extraction process of ECS and DCS obtained can serve as a solid basis for the development of industrial applications targeting the valorization and monetarization of chia seeds and in particular of the highly underused DCS.

\section{Declarations of interest}

None.

\section{Acknowledgements}

J. A. P. Coelho, R. M. Filipe and R. P. Stateva acknowledge the funding received from the European Union's Horizon 2020 research and innovation programme under the Marie Sklodowska-Curie grant agreement No. 778168. J. A. P. Coelho, and R. M. Filipe acknowledge the funding received from Fundação para a Ciência e a Tecnologia, Portugal, under projects UID/ECI/04028/ 2013 and UID/QUI/00100/2013. Chia seeds were generously supplied by PRIMARIA (www.primaria.biz).

\section{References}

[1] M.I. Capitani, S.M. Nolasco, M.C. Tomas, Food Hydrocoll. 61 (2016) 537, doi: http://dx.doi.org/10.1016/j.foodhyd.2016.06.008.

[2] B.L. Olivos-Lugo, M.A. Valdivia-Lopez, A. Tecante, Food Sci. Technol. Int. 16 (1) (2010) 89, doi:http://dx.doi.org/10.1177/1082013209353087.

[3] E. Reyes-Caudillo, A. Tecante, M.A. Valdivia-López, Food Chem. 107 (2) (2008) 656, doi:http://dx.doi.org/10.1016/j.foodchem.2007.08.062.

[4] P. Porras-Loaiza, M.T. Jiménez-Munguía, M.E. Sosa-Morales, E. Palou, A. LopezMalo, Int. J. Food Sci. Technol. 49 (2014) 571, doi:http://dx.doi.org/10.1111/ ijfs.12339.

[5] G. Barceló-Coblijn, E.J. Murphy, Progr. Lipid Res. 48 (6) (2009) 355, doi:http:// dx.doi.org/10.1016/j.plipres.2009.07.002.

[6] C. Galli, C.F. Marangoni, Prostag. Leukotr. Ess. Fatty Acids 75 (2006) 129, doi: http://dx.doi.org/10.1016/j.plefa.2006.05.007.

[7] G. Dąbrowski, I. Konopka, S. Czaplicki, M. Tanska, Eur. J. Lipid Sci. Technol. 119 (2017) 1, doi:http://dx.doi.org/10.1002/ejlt.201600209.

[8] B.T.F. de Mello, V.A. dos Santos García, C. da Silva, J. Food Process Eng. 40 (2015) 1, doi:http://dx.doi.org/10.1111/jfpe.12298.

[9] M.R. Segura-Campos, N. Ciau-Solís, G. Rosado-Rubio, L. Chel-Guerrero, D Betancur-Ancona, Agric. Sci. 5 (2014) 220, doi:http://dx.doi.org/10.4236/ as.2014.53025.

[10] R.G. Tolentino, M.L.R. Vega, S. Vega y León, J. Fontecha, L.M. Rodríguez, A.E. Medina, Rev. Cub. Plant. Med. 19 (2014) 199.

[11] A.B. Zanqui, D.R. de Morais, C.M. da Silva, J.M. Santos, L.U.R. Chiavelli, P.R.S. Bittencourt, M.N. Eberlin, J.V. Visentainer, L. Cardozo-Filho, M. Matsushita, J. Brazil Chem. Soc. 26 (2) (2015) 282, doi:http://dx.doi.org/10.5935/01035053.20140278 .

[12] G. Brunner, J. Food Eng. 67 (2005) 21, doi:http://dx.doi.org/10.1016/j. jfoodeng.2004.05.060.

[13] M. Wei, S. Hong, Y. Yang, J. Ind. Eng. Chem. 48 (2017) 202, doi:http://dx.doi.org/ 10.1016/j.jiec.2017.01.003.

[14] J.N. Moon, A.T. Getachew, A.S.M.T. Haque, P.S. Saravana, Y.J. Cho, D. Nkurunziza, B.S. Chun, J. Ind. Eng. Chem. 69 (2019) 217, doi:http://dx.doi.org/10.1016/j. jiec.2018.09.019.

[15] M. Topiar, M. Sajfrtova, J. Karban, H. Sovova, J. Ind. Eng. Chem. 77 (2019) 223, doi:http://dx.doi.org/10.1016/j.jiec.2019.04.041.

[16] O. Benito-Román, S. Varona, M.T. Sanz, S. Beltrán, J. Ind. Eng. Chem. 80 (2019) 273, doi:http://dx.doi.org/10.1016/j.jiec.2019.08.005.

[17] V.Y. Ixtaina, A. Vega, S.M. Nolasco, M.C. Tomás, M. Gimeno, E. Bárzana, A. Tecante, J. Supercrit. Fluids 55 (2010) 192, doi:http://dx.doi.org/10.1016/j. supflu.2010.06.003.

[18] V.Y. Ixtaina, F. Mattea, D.A. Cardarelli, M.A. Mattea, S.M. Nolasco, M.C. Tomás, J. Am. Oil Chem. Soc. 88 (2011) 289, doi:http://dx.doi.org/10.1007/s11746-0101670-2.

[19] J.A. Rocha Uribe, J.I. Novelo Pérez, H. Castillo Kauil, G. Rosado Rubio, C.G. Alcocer, J. Supercrit. Fluids 56 (2011) 174, doi:http://dx.doi.org/10.1016/j. supflu.2010.12.007.

[20] G. Scapin, E.R. Abaide, L.F. Nunes, M.A. Mazutti, R.G. Vendruscolo, R. Wagner, C. S. da Rosa, J. Supercrit. Fluids 127 (2017) 90, doi:http://dx.doi.org/10.1016/j supflu.2017.03.030.

[21] H. Sovova, R.P. Stateva, Ind. Eng. Chem. Res. 54 (2015) 4861, doi:http://dx.doi org/10.1021/acs.iecr.5b00741.

[22] M.P. Castro-Gomez, L.M. Rodriguez-Alcalá, M.V. Calvo, J. Romero, J.A. Mendiola, E. Ibanez, J. Fontecha, J. Dairy Sci. 97 (2014) 6719, doi:http://dx doi.org/10.3168/jds.2014-8128.

[23] D. Villanueva-Bermejo, F. Zahran, M.R. García-Risco, G. Reglero, T. Fornari, J. Supercrit. Fluids 119 (2017) 283, doi:http://dx.doi.org/10.1016/j.supflu.2016.10.005.

[24] P. Castro-Gómez, J. Fontecha, L.M. Rodríguez-Alcalá, Talanta 128 (2014) 518 , doi:http://dx.doi.org/10.1016/j.talanta.2014.05.051.

[25] Process Systems Enterprise, gPROMS. https://www.psenterprise.com/gproms/ . (Accessed 10 November 2018).

[26] V.Y. Ixtaina, M.L. Martínez, V. Spotorno, C.M. Mateo, D.M. Maestri, B.W.K. Diehl, S.M. Nolasco, M.C. Tomás, J. Food Compos. Anal. 24 (2011) 166, doi:http://dx. doi.org/10.1016/j.jfca.2010.08.006. 
[27] Y.P. Timilsena, J. Vongsvivut, R. Adhikari, B. Adhikari, Food Chem. 228 (2017) 394, doi:http://dx.doi.org/10.1016/j.foodchem.2017.02.021.

[28] K. Araus, E. Uquiche, J.M. del Valle, J. Food Eng. 92 (2009) 438, doi:http://dx.doi. org/10.1016/j.jfoodeng.2008.12.016.

[29] R.M. Couto, J. Fernandes, M.D.R.G. da Silva, P.C. Simões, J. Supercrit. Fluids 51 (2009) 159, doi:http://dx.doi.org/10.1016/j.supflu.2009.09.009.

[30] K.S. Duba, L. Fiori, J. Chem. Thermodyn. 100 (2016) 44, doi:http://dx.doi.org 10.1016/j.jct.2016.04.010.

[31] I. Gracia, M.T. García, J.F. Rodríguez, M.P. Fernández, A. de Lucas, J. Supercrit. Fluids 48 (2009) 189, doi:http://dx.doi.org/10.1016/j.supflu.2008.11.006.
[32] H.P. Cornelio-Santiago, C.B. Gonçalves, N.A. de Oliveira, A.L. de Oliveira, J. Supercrit. Fluids 128 (2017) 386, doi:http://dx.doi.org/10.1016/j.supflu.2017.05.030.

[33] J.P. Coelho, R.M. Filipe, M.P. Robalo, R.P. Stateva, J. Supercrit. Fluids 14 (2018) 68 doi:http://dx.doi.org/10.1016/j.supflu.2017.12.008.

[34] T. Holderbaum, J. Gmehling, Fluid Phase Equilibr. 70 (1991) 251, doi:http://dx. doi.org/10.1016/0378-3812(91)85038-V.

[35] C.R. Wilke, P. Chang, AIChE J. 1 (1955) 264, doi:http://dx.doi.org/10.1002/ aic.690010222. 